\title{
The Interplay between Charge Transfer, Rehybridization, and Atomic Charges in the Internal Geometry of Subunits in Noncovalent Interactions
}

\author{
Steve Scheiner* \\ Department of Chemistry and Biochemistry \\ Utah State University \\ Logan, UT 84322-0300
}

\begin{abstract}
When a noncovalent bond is formed, there is frequently some charge transfer from one subunit to the other. The interaction also causes changes in the atomic charges and hybridization patterns of bonding orbitals. The manner in which these various effects combine to cause elongations or contractions of bonds within the individual subunits is examined. In both the cases of $\mathrm{CH} \cdots \mathrm{O}$ $\mathrm{H}$-bonds and $\mathrm{P} \cdots \mathrm{N}$ pnicogen bonds, the bond length changes are consistent with the guiding principles generally known as Bent's rules.
\end{abstract}

*email: steve.scheiner@usu.edu

keywords: pnicogen bond; $\mathrm{PH} \cdot \mathrm{N}$ H-bond; hyperconjugation; rehybridization; Bent's rules 


\section{INTRODUCTION}

Since their inception some 50 years ago, Bent's rules ${ }^{[1-4]}$ have had a profound effect upon the way people think about molecular structure. This series of articles posited a clear correlation between various features of the geometry of a molecule and the hybridization of its central atom. In particular, if the central atom $\mathrm{A}$ is bonded to both $\mathrm{X}$ and $\mathrm{Y}$ substituents, increasing the electronegativity of $\mathrm{X}$ will elongate the A-X bond while shortening A-Y. Associated with this change is a decrease/increase in the s-character of the A-X/A-Y bonding orbitals. The change in $\mathrm{sp}^{\mathrm{x}}$ hybridization has implications for bond angles as well, since smaller $\mathrm{x}$ (greater s-character) is connected with larger bond angles. Lone electron pairs are considered, in a way, as limiting cases: bonds with a vanishingly small electronegativity on its substituent. As Bent pointed out, this trend is consistent with ideas about the inductive effect and opposite what one might expect if the reasoning were based purely upon repulsions between nonbonded atoms.

Although the ideas were originally formulated for first-row atoms A that satisfy the octet rule ${ }^{[5]}$, later incarnations treated other atom types, such as second-row $\mathrm{P}$ atoms, as for example a work ${ }^{[6]}$ which emphasized differences in electronegativity, as opposed to absolute electronegativities themselves. The ideas have been further extended to metals as central atoms ${ }^{[7]}$ where a new distinction was noted. Whereas main group atoms form $\mathrm{sp}^{\mathrm{x}}$ hybrid orbitals where the $\mathrm{s}$ and $\mathrm{p}$ orbitals are drawn from the same principal quantum number $n$, hybrids of transition metals typically involve d-orbitals derived from a lower value of $n$. The latter are usually of lower energy than the s orbitals with which they combine so that some of the Bent rules are reversed. In other words, formation of a bond with a more electropositive atom will indeed enhance participation of the lower energy orbital in either case, just as Bent had originally proposed. When the central atom is of the main group, and forms $\mathrm{sp}^{\mathrm{x}}$ hybrids, this rule enhances s participation. But the same idea will increase contribution of the lower-energy d-orbitals in the $\mathrm{sd}^{\mathrm{X}}$ hybrids of the transition metals. It is for this reason that Jonas et al ${ }^{[7]}$ had found that Cl-A-Cl bond angles are smaller than $\mathrm{C}-\mathrm{A}-\mathrm{C}$ angles when $\mathrm{A}$ is a main group atom, but that the opposite is true when $\mathrm{A}$ is a transition metal.

The above cases describe the situation within the context of a single molecule, held together by strong covalent bonds. However, the Bent rules appear to retain their relevance even when the much weaker noncovalent bonds between molecules are considered. These rules have been invoked repeatedly in the case of H-bonds for example. The next sections elaborate on these issues for two specific sorts of noncovalent interactions. The first situation is a particularly weak sort of $\mathrm{H}$-bond, involving $\mathrm{CH}$ as proton donor, in contrast to the much more common situation of a $\mathrm{OH}$ or $\mathrm{NH}$ donor. These $\mathrm{CH} \cdots \mathrm{X}$ interactions have generated especial interest in that some of them behave in a manner diametrically opposed to the more conventional H-bonds. Section II describes how Bent's rules have shed a great deal of light on the underlying source of this contrary behavior. The second scenario involves an attractive interaction between $\mathrm{P}$ and $\mathrm{N}$ atoms that has generated recent interest, a so-called pnicogen bond. Data are calculated and analyzed in Section III to evaluate the applicability of the Bent principles to this noncovalent bond, which might be considered a rather stringent test. 


\section{A PAST EXAMPLE: C-H H-BONDS}

One of the more interesting and useful sets of applications of Bent's rule has involved the weaker variety of $\mathrm{H}$-bond wherein a $\mathrm{CH}$ group acts as proton donor. In particular, the $\mathrm{CH}$ bond is frequently shortened in such interactions, in contrast to the lengthening which is the usual observation in the proton donor molecule. In common with this bond contraction one frequently notes a blue shift of the stretching frequency of this bond, again opposite to the red shift which is typically deemed characteristic of $\mathrm{H}$-bonds ${ }^{[8-11]}$. Due to this contrary behavior, the $\mathrm{CH} \cdots \mathrm{X}$ interaction has gone by several names, such as anti H-bond ${ }^{[12]}$, or improper and blue-shifting $\mathrm{H}$ bond, and has been the object of a good deal of theoretical scrutiny.

Shifts to the blue were noted ${ }^{[13-15]}$ when halogenated methane served as proton donor to a set of small $\mathrm{O}$ or $\mathrm{N}$-acceptors, along with the NMR chemical shifts expected for conventional Hbonds ${ }^{[16]}$. The same direction of shift occurred when the donor was one of a series of amino acid residues ${ }^{[17]}$. On the other hand, a more careful examination of how the shift might be correlated with the hybridization of the $\mathrm{C}$ atom revealed that such blue shifts are typically associated with $\mathrm{sp}^{3}$ hybridization, while sp-systems usually shift to the red. Intermediate $\mathrm{sp}^{2}$ cases may shift in either direction, but by a small amount in any case, as further exemplified by aromatic $\mathrm{CH}$ donors. While this hybridization pattern is a good rule of thumb, there are exceptions to it in the literature. Nonetheless, this connection with hybridization does bring to mind the Bent rules where it is a major ingredient.

There have been numerous attempts to explain the direction of frequency shift and/or $\mathrm{CH}$ bond length change and on various conceptual bases. Our own group suggested the question as to whether a $\mathrm{C}-\mathrm{H}$ bond stretches or contracts when engaged in a $\mathrm{H}$-bond is the result of a delicate balance between opposing forces, true also in the case of a conventional H-bond. The contraction noted in many $\mathrm{C}-\mathrm{H}$ bonds is simply a result ${ }^{[18]}$ of the intermolecular exchange repulsion, which pushes the bridging proton in toward the $\mathrm{C}$ atom, winning out over the other forces that tend toward a longer bond, most notably the electrostatic attraction. This central idea of a balance between opposing forces has been confirmed by several other groups ${ }^{[19-23]}$, some of whom used different conceptual frameworks but arrived at the same conclusion.

The ideas enunciated by Bent have been particularly fruitful in understanding the phenomenon of blue-shifting H-bonds. As in the earlier work, the direction of shift can be attributed to two competing forces. Rehybridization of the central (in this case $\mathrm{C}$ ) atom that increases the s-character of the $\mathrm{C}-\mathrm{H}$ bond would be expected, according to these concepts, to shorten the $\mathrm{C}-\mathrm{H}$ bond. Acting in the opposite direction would be any charge that is transferred (also known as hyperconjugation) into the $\mathrm{CH} \sigma^{*}$ antibonding orbital that would weaken and thus lengthen this bond.

As an early example of application of these ideas, one group ${ }^{[24]}$ proposed the $\mathrm{CH}$ bond contraction might be due to a repulsion which would enlarge the relevant angle, and thereby rehybridize the $\mathrm{C}$ atom. The ensuing greater s-character in the $\mathrm{C}-\mathrm{H}$ bond might strengthen it, via the Bent effect, causing it to contract and shift its stretch to higher frequency. This language was elaborated and refined in 2003 by Alabugin et al ${ }^{[25]}$ who examined a full variety of $\mathrm{CH} \cdot \mathrm{X}$ 
bonds, both red and blue-shifting, and added the way in which atomic charges might influence the bond length. The degree of hybridization was elucidated via natural bond orbital (NBO) formalism, as was the hyperconjugation. An important contribution arising from this work was the strong sensitivity of bond length to hybridization, as even a change of only $1 \%$ in the percent s-character of a C-H bond can change its length by more than $2 \mathrm{~m} \AA$. The concepts were robust enough that the authors were able to extend them to other proton donors, e.g. $\mathrm{SH}, \mathrm{PH}$, and NH groups.

More recent work has further elaborated these concepts. Yang et al found $\mathrm{CH} \cdots \mathrm{N} \mathrm{H}$-bonds of both types, red and blue shifting, in complexes of $\mathrm{CH}_{3} \mathrm{CHO}$ with $\mathrm{NH}_{3}{ }^{[26]}$ and with $\mathrm{HNO}^{\text {[27] }}$ and were able to explain the distinction on the basis of relative amounts of hyperconjugation and rehybridization. Their work reiterated the sensitivity to even small changes in hybridization, some as minute as $0.1 \%$. Later work extended the idea to both $\mathrm{NH}$ and $\mathrm{SH}$ proton donors ${ }^{[28,29]}$. Pluháčková and Hobza ${ }^{[30]}$ noted that whereas the $\mathrm{CH}$ bond of halothane shifts to the red when complexed with acetone, fluoroform shifts its $\mathrm{CH}$ bond to the blue. They found that the competition between hyperconjugation and rehybridization explained this distinction, as the two effects reinforced one another with one molecule, and opposed each other in the other. The authors noted that this Bent treatment offered an excellent means of understanding the basic chemical physics, superior to symmetry-adapted perturbation theory.

A further refinement which distinguished intramolecular from intermolecular charge shifts was brought to bear by $\mathrm{Li}^{[31]}$ in comparing and understanding the shifts of proton donors $\mathrm{F}_{3} \mathrm{CH}$, $\mathrm{F}_{2} \mathrm{HCH}, \mathrm{ONH}, \mathrm{SNH}, \mathrm{F}_{2} \mathrm{NH}$, and $\mathrm{CH}_{2} \mathrm{NH}$. These ideas were later used to help analyze interactions involving anionic proton acceptors ${ }^{[32]}$ where the author noted a clear distinction that whereas linear $\mathrm{H}$-bonds formed with a number of $\mathrm{CH}$ proton donors shifted to the red, those systems engaged in bifurcated $\mathrm{H}$-bonds shifted in the opposite direction. The former were dominated by a high degree of direct intermolecular hyperconjugation, amplified by the anionic character of the electron donor. In contrast, it was rehybridization, supplemented by a diminished intramolecular hyperconjugation that occurred in the latter.

Zhang et al ${ }^{[33]}$ extended the Bent ideas to $\mathrm{X}-\mathrm{H}$ bonds that are not directly involved in the $\mathrm{H}$ bonds themselves. Even in the absence of such bonds, they presented evidence that the same basic concepts of hyperconjugation and rehybridization were just as applicable in understanding the red or blue shifts of these $\mathrm{C}$-H bonds in complexes of formamide with $\mathrm{HF}, \mathrm{H}_{2} \mathrm{O}, \mathrm{NH}_{3}$, and $\mathrm{H}_{2} \mathrm{~S}$. Their results echoed earlier studies that even small changes in the sp hybridization, $0.1-$ $0.4 \%$, are sufficient to produce observable effects on the $\mathrm{C}-\mathrm{H}$ bond length.

A later set of computations ${ }^{[34]}$, taking ethers as the proton acceptor in complexes with various haloforms, pointed out a relationship between the amount of frequency shift and internal $\theta(\mathrm{COC})$ bond angle within the ether. The authors attributed this observation to a larger degree of s-character in the $\mathrm{O}$ atom's lone pair, which in turn diminishes the charge transfer into the $\mathrm{CH} \sigma^{*}$ antibond. This work was influential in that it extended the Bent ideas regarding the $\mathrm{C}-\mathrm{H}$ stretching mode to not only the proton donor molecule but also the proton acceptor partner. 
Small changes in hybridization were also noted by Grabowski ${ }^{[35]}$ who compared the classic $\mathrm{CH}$ red and blue shifters, $\mathrm{sp} \mathrm{HC} \equiv \mathrm{CH}$ and $\mathrm{sp}^{3} \mathrm{~F}_{3} \mathrm{CH}$, respectively, and found strong correlations between the Bent parameters and total interaction energy. This work went further and tied together the aforementioned quantities with several Atoms in Molecules measures of the electron density topography.

\section{PNICOGEN BONDS}

Given the contributions of the Bent ideas to unravelling the nature of blue-shifting H-bonds, it is tempting to bring these same concepts to bear on a new and different set of noncovalent interactions. Recent work in this laboratory has focused on an intermolecular interaction between $\mathrm{P}$ and $\mathrm{N}$ atoms which interact directly with one another in the $\mathrm{PH}_{3} / \mathrm{NH}_{3}$ heterodimer ${ }^{\text {[36] }}$. The bonding arises in large part from charge transfer/hyperconjugation from the $\mathrm{N}$ lone pair into the $\sigma^{*}$ antibond of the $\mathrm{P}-\mathrm{H}$ bond, in particular the lobe of the $\sigma^{*}$ orbital that is situated on the $\mathrm{P}$ end of the $\mathrm{P}-\mathrm{H}$ bond. Although this interaction is less than $2 \mathrm{kcal} / \mathrm{mol}$, it is enhanced ${ }^{[37]}$ by the replacement of the $\mathrm{H}$ atom of the phosphine by a more electronegative group. The replacement of $\mathrm{H}$ atoms that are not involved in the interaction has little additional effect. Later calculations ${ }^{[38]}$ showed that $\mathrm{S}$ can also serve as a viable electron donor, as can a variety of $\mathrm{C}-\mathrm{C} \pi$ bonds and aromatic systems. Second row atoms other than $\mathrm{P}$, viz. $\mathrm{S}$ and $\mathrm{Cl}$ are alternate electron acceptors, as is $\mathrm{As}^{[39]}$, with only minor changes in bond strength.

While there has been some careful analysis of the forces that contribute to pnicogen bonds of this sort, the Bent ideas of hyperconjugation and rehybridization have not yet been tested. The past example of $\mathrm{CH} \mathrm{H}$-bonds described above illustrated how the length of the $\mathrm{C}-\mathrm{H}$ bond is influenced by these two effects, sometimes reinforcing and other times opposing. In the case of the pnicogen bonds, the $\mathrm{P}$ and $\mathrm{N}$ atoms face each other directly, with a $\mathrm{H}$ atom rotating out of the way. Nevertheless, charge is transferred into the $\sigma^{*} \mathrm{PH}$ antibonding orbital. How does this hyperconjugation affect the length of this $\mathrm{P}-\mathrm{H}$ bond? Secondly, are there changes in the s/p character of the P-H bonding orbital, and if so are these changes consistent with Bent's rules?

\section{A. METHODS}

The Gaussian 09 program ${ }^{[40]}$ was used to carry out calculations. The level of theory applied was MP2/aug-cc-pVDZ which has demonstrated good accuracy when compared with experiment and higher-level calculations in the past ${ }^{[37,41-49]}$. The binding energy is defined as the difference in energy between the dimer and the sum of the optimized energies of the isolated monomers. Binding energies were corrected for basis set superposition error by the counterpoise procedure [50,51]. The molecular orbitals were localized via the Natural Bond Orbital (NBO) procedure ${ }^{[52,53]}$, so as to extract hybridization and charge transfer data.

\section{B. RESULTS}

The testing begins with the simple $\mathrm{PH}_{3}$ molecule, bound to $\mathrm{NH}_{3}$. Previous work has shown [36] that the pnicogen bonded $\mathrm{H}_{3} \mathrm{P} \cdots \mathrm{NH}_{3}$ represents the global minimum of this heterodimer, and that a $\mathrm{H}$-bonded $\mathrm{H}_{2} \mathrm{PH} \cdots \mathrm{NH}_{3}$ structure is a secondary minimum. Evaluation of the Bent and other aspects of these two complexes thus permit a detailed comparison of the pnicogen and $\mathrm{H}$ bonded noncovalent bonds. Substitution of one of the $\mathrm{H}$ atoms of $\mathrm{PH}_{3}$ substantially strengthens 
both the pnicogen $\left(\mathrm{FH}_{2} \mathrm{P} \cdots \mathrm{NH}_{3}\right)$ and $\mathrm{H}$-bonded $\left(\mathrm{FHPH} \cdots \mathrm{NH}_{3}\right)$ complexes. Comparison here facilitates an examination of the validity of the principles emanating from the study of the simple hydrides to more strongly bound dimers.

1- $\underline{\mathrm{PH}}_{3} \underline{\mathrm{NH}}_{3}$

The optimized geometries of the two minima of the $\mathrm{PH}_{3} / \mathrm{NH}_{3}$ heterodimer are illustrated in Fig 1a and 1b, and some relevant quantities are summarized in Table 1. The first column reports the value of each parameter in the monomer. The second and third columns contain the change in the monomer quantities upon forming the pnicogen and hydrogen-bonded dimers, respectively. For example, as displayed in the second row of Table 1, the $\mathrm{r}(\mathrm{PH})$ bond lengths in the $\mathrm{PH}_{3}$ monomer are $1.4261 \AA$. Upon formation of the pnicogen bonded $(\mathrm{HP} \cdots \mathrm{N})$ dimer, the P$\mathrm{H}$ bond of the $\mathrm{H}$ atom turned away from the partner $\mathrm{NH}_{3}$ molecule is elongated by $0.0028 \AA$. There is a concurrent contraction of the other two $\mathrm{P}-\mathrm{H}$ bonds ( $\mathrm{H}$ ' refers to nonparticipating atoms) by $0.0019 \AA$. The effects of complexation are quite different in the H-bonded $\mathrm{H}_{2} \mathrm{PH} \cdots \mathrm{NH}_{3}$ structure: The bridging P-H bond is stretched by only $0.0007 \AA$, while the other two $\mathrm{P}-\mathrm{H}$ bonds are also elongated, by the slightly larger amount of $0.0009 \AA$. In summary, while the participating $\mathrm{P}-\mathrm{H}$ bonds in the pnicogen and hydrogen-bonded complexes both grow longer, the former is elongated four times more than is the latter.

The frequencies in the next two rows are consistent with the bond length patterns, in that those bonds undergoing an elongation also see a red shift of the corresponding stretching frequency, and vice versa for a bond contraction. Of course, the occurrence of three $\mathrm{H}$ atoms on the $\mathrm{PH}_{3}$ molecule partially obscures a direct one-to-one correspondence between a given bond and its particular stretch, due to the coupling between their motions. The PH stretch was taken here to be the asymmetric mode that involves one $\mathrm{H}$ atom in particular, and $\mathrm{PH}$ ' as the asymmetric stretch involving the other two $\mathrm{H}$ atoms.

The next few rows contain electronic data that can help to explain this behavior. The NBO atomic charge of $\mathrm{P}$ remains almost unchanged by the formation of the pnicogen bond, but becomes substantially more negative when engaged in a H-bond. Perhaps more to the point, the participating $\mathrm{H}$ atom of $\mathrm{PH}_{3}$ becomes more negatively charged in the pnicogen bond, and quite a bit more positive in the $\mathrm{H}$-bond. The axiom that a more negatively charged $\mathrm{H}$ atom should be connected by a longer $\mathrm{P}-\mathrm{H}$ bond is verified in the pnicogen bond. However, the opposite is true in the $\mathrm{H}$-bond wherein $\mathrm{P}-\mathrm{H}$ is elongated, albeit by only a small amount, despite a much more positively charged $\mathrm{H}$ atom. The reader might note as well that the behavior of the nonparticipating H' atoms is consistent with this part of Bent's rule: the more positively charged $\mathrm{H}^{\prime}$ atom in the HP $\cdot \mathrm{N}$ complex leads to a shorter $\mathrm{P}-\mathrm{H}^{\prime}$ bond, whereas the opposite is true in the H-bond.

Another aspect of Bent's rule deals with the hybridization of the P-H bonds. The first column of Table 1 indicates these bonds are composed of $15.8 \% \mathrm{~s}$ and $82.7 \% \mathrm{p}$ in the uncomplexed $\mathrm{PH}_{3}$ monomer. The next two columns indicate there is a small increase in $\mathrm{p}$ character for the HP $\cdots \mathrm{N}$ complex, and the reverse is true in the $\mathrm{H}$-bonded $\mathrm{OH} \cdots \mathrm{N}$ structure. The reduced s character in the former case should lead to a longer $\mathrm{P}-\mathrm{H}$ bond, which is in fact 
observed. Again, the H-bonded complex is the outlier, as the increased s character ought to shorten the $\mathrm{P}-\mathrm{H}$ bond, but a lengthening is observed instead. As in the case of the atomic charges, the nonparticipating H' atoms behave strictly according to Bent's rule. The greater/lesser degree of s character is reflected in a shortening/lengthening of the P-H' bonds.

The last factor to be considered is the hyperconjugation which is essentially equivalent to charge transfer. Both the pnicogen and hydrogen-bonded systems are stabilized in large measure by a transfer of charge from the $\mathrm{N}$ lone pair to a $\sigma^{*} \mathrm{P}-\mathrm{H}$ antibonding orbital. Any such increase in $\sigma^{*}$ population would be expected to lengthen the associated $\mathrm{P}-\mathrm{H}$ bond. This transfer is assessed via the NBO procedure and may be seen in the last row of Table 1. A graphic depiction of this transfer, illustrating the specific NBO orbitals involved, is provided by Fig 2, where the occupied $\mathrm{N}$ lone pair is indicated by the filled lobe, and the vacant $\sigma^{*}$ orbitals by the unfilled lobes. The transfer of 2.0 me in the pnicogen bonded system adds to, and thus reinforces, the rehybridization-induced lengthening that is the direct result of the diminished s character in this bond. The consequence is a large bond stretch. This same charge transfer may be seen to be more than twice as large for the H-bond. The high degree of bond stretch caused by this hyperconjugation is able to more than compensate for the contraction that is associated with the greater s character of the $\mathrm{P}-\mathrm{H}$ bond, resulting in a small bond elongation.

Bent's rules would normally predict that the elongation of one $\mathrm{P}-\mathrm{H}$ bond in $\mathrm{PH}_{3}$ ought to be associated with the shortening of the other. This pattern is in fact observed in the pnicogen bonded complex, wherein P-H elongates by $2.8 \mathrm{me}$, while the nonparticipating P-H' bond contracts by 1.9 me. On the other hand, both of these bonds are elongated in the H-bonded $\mathrm{PH} \cdots \mathrm{N}$ structure, which might perhaps be attributed to the large influence of the charge transfer which pushes the elongation of $\mathrm{r}(\mathrm{PH})$, in opposition to the rehybridization that tends toward a shorter bond.

\section{2- Fluorosubstituted $\mathrm{FPH}_{2} / \mathrm{NH}_{3}$ dimer}

The fluorosubstituted $\mathrm{FPH}_{2}$ molecule forms a considerably stronger pnicogen bond with $\mathrm{NH}_{3}$ and thus offers in some ways a more stringent test of the Bent postulates. The global minimum for this pair is illustrated in Fig 1c where it may be seen that the F atom is turned away from the partner $\mathrm{NH}_{3}$ molecule. In order to draw a contrast with the $\mathrm{H}$-bond, it must first be acknowledged that such a geometry does not represent a minimum on the potential energy surface of the $\mathrm{FPH}_{2} / \mathrm{NH}_{3}$ dimer. The structure in Fig 1d was obtained by restricting the bridging $\mathrm{H}$ atom to lie along the $\mathrm{P} \cdots \mathrm{N}$ axis, optimizing all other geometrical parameters. As in the previous case, the $\mathrm{H}$ atom involved in the $\mathrm{H}$-bond is labeled as $\mathrm{H}$, and the uninvolved $\mathrm{H}$ atom(s) as H'.

The second row of Table 2 illustrates that the P-F bond is stretched, whether it is involved in a FP $\cdots \mathrm{N}$ pnicogen bond, or whether it is a nonparticipating peripheral atom as in Fig 1d. The bridging $\mathrm{PH}$ bond of the $\mathrm{H}$-bonded structure is compressed, and even more so in the case of the pnicogen bond, and the non-bridging PH bond length of the H-bonded complex is changed very little. The stretching frequencies are again consistent with the bond length changes. The large 
elongation of the P-F bond in the FP...N complex is associated with a $65 \mathrm{~cm}^{-1}$ red shift in its stretching frequency, a shift which is much smaller in the $\mathrm{PH} \cdot \mathrm{N}$ dimer.

The $\mathrm{F}$ atom takes on an increased negative charge in either complex, especially in the FP $\cdots \mathrm{N}$ geometry. This enhanced charge is consistent with the stretch of the P-F bond, which is also

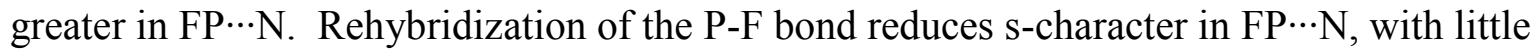
effect in $\mathrm{PH} \cdots \mathrm{N}$. These changes are consistent with the F charge pattern, lengthening in FP $\cdots \mathrm{N}$, and a much smaller change in $\mathrm{PH} \cdots \mathrm{N}$. The bridging $\mathrm{H}$ in $\mathrm{PH} \cdots \mathrm{N}$ becomes more positive, consistent with the shortening of its bond to $\mathrm{P}$. This contraction might also be inferred by the rise in s character. Note, however, that the amount of bond contraction, only $2 \mathrm{~m} \AA$, is surprisingly small considering the large rise in $\mathrm{H}$ atomic charge and s character (see below). A like increase in s percentage occurs in the $\mathrm{P}-\mathrm{H}$ bonds of the FP... N complex, and the bond is shortened, by even more than in $\mathrm{PH} \cdots \mathrm{N}$, even though the $\mathrm{H}$ atomic charge is not much affected by formation of this complex. The charge of the peripheral $\mathrm{H}$ atom remains almost constant in $\mathrm{PH} \cdots \mathrm{N}$, as does its hybridization, explaining the absence of significant change in its $\mathrm{PH}$ bond

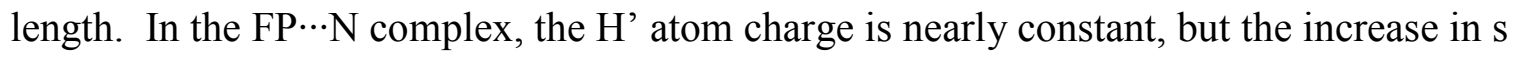
character explains its bond shortening.

The final two rows of Table 2 reveal a great deal of hyperconjugative charge transfer into the $\mathrm{P}-\mathrm{F}$ antibond of the FP..N complex. The resulting bond lengthening effect, when coupled with the aforementioned rehybridization that also tends toward a longer bond, has the consequence of a highly elongated $\mathrm{P}-\mathrm{F}$ bond, by nearly $30 \mathrm{~mA}$. In the case of the H-bonded structure, there is little charge transfer into the PF antibonding orbital, and so the small P-F bond elongation may be attributed to the slightly more negative charge on the $\mathrm{F}$ atom and the small rehybridization. Of course, there may be other effects in play, besides the ones being considered here. The charge transfer into the bridging $\mathrm{PH} \sigma^{*}$ orbital in the H-bonded complex is considerably smaller. Its pull toward a longer P-H bond is successfully opposed by the shortening effects of rehybridization. But because these two forces act at cross purposes, the net effect is only a small change in $\mathrm{r}(\mathrm{PH})$. There is also a certain amount of charge transfer from the $\mathrm{N}$ lone pair into the $\sigma^{*}$ antibonds of the nonparticipating P-H bonds in the FP- $\cdots \mathrm{N}$ complex. The lengthening effect of this hyperconjugation tempers the contraction which would result if the increased s character acted on its own.

As in the simpler hydride $\mathrm{PH}_{3} / \mathrm{NH}_{3}$ case, there is a compensation between the internal bond lengths in the pnicogen-bonded complex of $\mathrm{FPH}_{2} / \mathrm{NH}_{3}$. That is, the stretched $\mathrm{P}-\mathrm{F}$ bond is associated with contractions in the two P-H bonds. The same is true in the H-bonded complex in that the bridging $\mathrm{P}-\mathrm{H}$ bond is shortened while $\mathrm{P}-\mathrm{F}$ is elongated. The two $\mathrm{P}-\mathrm{H}^{\prime}$ bond lengths change very little, stretching by much less than $1 \mathrm{~m} \AA$.

It should be noted that the applicability of Bent's rules have been evaluated in related systems such as halogen bonds ${ }^{[54-56]}$, and dihalogen and halogen-hydride bonds ${ }^{[57]}$, and found to hold great merit.

In conclusion, the Bent rules have a great deal to offer in terms of our understanding of the noncovalent interactions that are much weaker than the intramolecular phenomena for which 
they were first devised. The interplay between rehybridization and charge transfer has provided a fertile ground to explain the distinction between those H-bonds in which the proton-donor covalent bond lengthens and shifts its stretching frequency to the red, and other H-bonds which undergo exactly opposite changes, in spite of what would appear at first sight to be strong resemblance. The data presented here have shown that the Bent principles are applicable as well to the noncovalent pnicogen bonds where there is no $\mathrm{H}$ atom bridging the $\mathrm{P}$ and $\mathrm{N}$ atoms of the two molecules. Due to the weakness of the intermolecular forces, the magnitudes of the charge shifts, atomic charge perturbations, and changes in hybridization patterns are quite small, but nonetheless strongly indicative of the observed changes of bond length, all consistent with the rules originally proposed by Bent more than fifty years ago. 


\section{REFERENCES}

[1] H. A. Bent, J. Chem. Phys. 1960, 33, 1258.

[2] H. A. Bent, J. Chem. Phys. 1960, 33, 1259.

[3] H. A. Bent, J. Chem. Phys. 1960, 33, 1260.

[4] H. A. Bent, Chem. Rev. 1961, 67, 275.

[5] H. A. Bent, J. Chem. Ed. 1960, 37, 616.

[6] J. E. Huheey, Inorg. Chem. 1981, 20, 4033.

[7] V. Jonas, C. Boehme, G. Frenking, Inorg. Chem. 1996, 35, 2097.

[8] S. Pinchas, J. Phys. Chem. 1963, 67, 1862.

[9] W. G. Schneider, H. J. Bernstein, Trans. Faraday Soc. 1956, 52, 13.

[10] G. Trudeau, J.-M. Dumas, P. Dupuis, M. Guerin, C. Sandorfy. In Top. Curr. Chem., 1980, p 91.

[11] M. Budesinsky, P. Fiedler, Z. Arnold, Synthesis 1989, 11, 858.

[12] P. Hobza, V. Spirko, H. L. Selzle, E. W. Schlag, J. Phys. Chem. A 1998, 102, 2501.

[13] Y. Gu, T. Kar, S. Scheiner, J. Mol. Struct. 2000, 552, 17.

[14] S. Scheiner. In Theory and Applications of Computational Chemistry: The First 40 Years; Dykstra, C. E.; Frenking, G.; Kim, K. S.; Scuseria, G. E., Eds.; Elsevier: Amsterdam, 2005, p 831.

[15] S. Scheiner. In Hydrogen Bonding - New Insights; Grabowski, S. J., Ed.; Springer, 2006, p 263.

[16] Y. Gu, T. Kar, S. Scheiner, J. Mol. Struct. (Theochem) 2000, 500, 441.

[17] S. Scheiner, T. Kar, Y. Gu, J. Biol. Chem. 2001, $276,9832$.

[18] Y. Gu, T. Kar, S. Scheiner, J. Am. Chem. Soc. 1999, 121, 9411.

[19] L. Pejov, K. Hermansson, J. Chem. Phys. 2003, 119, 313.

[20] W. Qian, S. Krimm, J. Phys. Chem. A 2002, 106, 11663.

[21] X. Li, L. Liu, H. B. Schlegel, J. Am. Chem. Soc. 2002, 124, 9639.

[22] J. Joseph, E. D. Jemmis, J. Am. Chem. Soc. 2007, 129, 4620.

[23] G. Prampolini, L. Carbonaro, G. Feng, L. Evangelisti, W. Caminati, I. Cacelli, J. Chem. Theory Comput. 2014, 10, 2204.

[24] I. E. Boldeskul, I. F. Tsymbal, E. V. Ryltsev, Z. Latajka, A. J. Barnes, J. Mol. Struct. 1997, 436, 167.

[25] I. V. Alabugin, M. Manoharan, S. Peabody, F. Weinhold, J. Am. Chem. Soc. 2003, 125, 5973.

[26] Y. Yang, W. Zhang, S. Pei, J. Shao, W. Huang, X. Gao, J. Mol. Struct. (Theochem) 2005, $732,33$.

[27] Y. Yang, W. Zhang, X. Gao, Int. J. Quantum Chem. 2006, 106, 1199.

[28] Y. Yang, W.-J. Zhang, X.-M. Gao, Chin. J. Chem. 2006, 24, 887.

[29] Y. Yang, Int. J. Quantum Chem. 2009, 109, 266.

[30] K. Pluháková, P. Hobza, ChemPhysChem. 2007, 8, 1352.

[31] A. Y. Li, J. Chem. Phys. 2007, 126, 154102.

[32] A. Y. Li, J. Mol. Struct. (Theochem) 2008, 862, 21.

[33] G. Zhang, A. Ji, D. Chen, J. Mol. Struct. (Theochem) 2008, 853, 89.

[34] A. Mukhopadhyay, P. Pandey, T. Chakraborty, J. Phys. Chem. A 2010, 114, 5026.

[35] S. J. Grabowski, J. Phys. Chem. A 2011, 115, 12789.

[36] S. Scheiner, J. Chem. Phys. 2011, 134, 094315.

[37] S. Scheiner, J. Phys. Chem. A 2011, 115, 11202. 
[38] S. Scheiner, U. Adhikari, J. Phys. Chem. A 2011, 115, 11101.

[39] S. Scheiner, J. Chem. Phys. 2011, 134, 164313.

[40] M. J. Frisch, G. W. Trucks, H. B. Schlegel, G. E. Scuseria, M. A. Robb, J. R. Cheeseman, G. Scalmani, V. Barone, B. Mennucci, G. A. Petersson, H. Nakatsuji, M. Caricato, X. Li, H. P. Hratchian, A. F. Izmaylov, J. Bloino, G. Zheng, J. L. Sonnenberg, M. Hada, M. Ehara, K. Toyota, R. Fukuda, J. Hasegawa, M. Ishida, T. Nakajima, Y. Honda, O. Kitao, H. Nakai, T. Vreven, J. Montgomery, J. A., J. E. Peralta, F. Ogliaro, M. Bearpark, J. J. Heyd, E. Brothers, K. N. Kudin, V. N. Staroverov, R. Kobayashi, J. Normand, K. Raghavachari, A. Rendell, J. C. Burant, S. S. Iyengar, J. Tomasi, M. Cossi, N. Rega, J. M. Millam, M. Klene, J. E. Knox, J. B. Cross, V. Bakken, C. Adamo, J. Jaramillo, R. Gomperts, R. E. Stratmann, O. Yazyev, A. J. Austin, R. Cammi, C. Pomelli, J. W. Ochterski, R. L. Martin, K. Morokuma, V. G. Zakrzewski, G. A. Voth, P. Salvador, J. J. Dannenberg, S. Dapprich, A. D. Daniels, O. Farkas, J. B. Foresman, J. V. Ortiz, J. Cioslowski, D. J. Fox. Wallingford, CT, 2009.

[41] R. M. Osuna, V. Hernández, J. T. L. Navarrete, E. D’Oria, J. J. Novoa, Theor. Chem. Acc. 2011, 128, 541.

[42] M. G. Chudzinski, C. A. McClary, M. S. Taylor, J. Am. Chem. Soc. 2011, 133, 10559.

[43] Y. Zeng, X. Zhang, X. Li, S. Zheng, L. Meng, Int. J. Quantum Chem. 2011, 111, 3725.

[44] J. Wu, Int. J. Quantum Chem. 2011, 111, 4247.

[45] D. Hauchecorne, N. Nagels, B. J. van der Veken, W. A. Herrebout, Phys. Chem. Chem. Phys. 2012, 14, 681.

[46] J. Nadas, S. Vukovic, B. P. Hay, Comput. Theor. Chem. 2012, 988, 75.

[47] Q. Zhao, D. Feng, Y. Sun, J. Hao, Z. Cai, Int. J. Quantum Chem. 2011, 111, 3881.

[48] E. Munusamy, R. Sedlak, P. Hobza, ChemPhysChem. 2011, 12, 3253.

[49] D. Hauchecorne, A. Moiana, B. J. van der Veken, W. A. Herrebout, Phys. Chem. Chem. Phys. 2011, 13, 10204.

[50] S. F. Boys, F. Bernardi, Mol. Phys. 1970, 19, 553.

[51] Z. Latajka, S. Scheiner, J. Chem. Phys. 1987, 87, 1194.

[52] A. E. Reed, F. Weinhold, L. A. Curtiss, D. J. Pochatko, J. Chem. Phys. 1986, 84, 5687.

[53] A. E. Reed, L. A. Curtiss, F. Weinhold, Chem. Rev. 1988, 88, 899.

[54] S. J. Grabowski, J. Phys. Chem. A 2011, 115, 12340.

[55] S. J. Grabowski, Phys. Chem. Chem. Phys. 2013, 15, 7249.

[56] S. J. Grabowski, Theor. Chem. Acc. 2013, 132, 1347.

[57] S. J. Grabowski, J. Phys. Chem. A 2012, 116, 1838. 
Table 1. Effects of complexation with $\mathrm{NH}_{3}$ upon properties of $\mathrm{PH}_{3}$ molecule

\begin{tabular}{|l|l|l|l|}
\hline & monomer & $\Delta \mathrm{HP} \cdots \mathrm{N}$ & $\Delta \mathrm{PH} \cdots \mathrm{N}$ \\
\hline$-\Delta \mathrm{E}, \mathrm{kcal} / \mathrm{mol}$ & & 2.1 & 1.5 \\
\hline $\mathrm{r}(\mathrm{P}-\mathrm{H}), \AA$ & 1.426 & 0.003 & 0.001 \\
\hline $\mathrm{r}\left(\mathrm{P}-\mathrm{H}^{\prime}\right), \AA$ & 1.426 & -0.002 & 0.001 \\
\hline$v(\mathrm{P}-\mathrm{H}), \mathrm{cm}^{-1}$ & 2471.2 & -22.6 & -6.5 \\
\hline$v\left(\mathrm{P}-\mathrm{H}^{\prime}\right), \mathrm{cm}^{-1}$ & 2470.6 & 9.9 & -5.9 \\
\hline $\mathrm{q}(\mathrm{H}), \mathrm{e}$ & -0.035 & -0.012 & 0.035 \\
\hline $\mathrm{q}\left(\mathrm{H}^{\prime}\right), \mathrm{e}$ & -0.035 & +0.004 & -0.006 \\
\hline $\mathrm{q}(\mathrm{P}), \mathrm{e}$ & 0.106 & -0.001 & -0.029 \\
\hline $\mathrm{P}-\mathrm{H} \mathrm{s}^{\circ}$ & 15.8 & -0.4 & 1.1 \\
\hline $\mathrm{P}-\mathrm{H} \mathrm{p} \%$ & 82.7 & 0.4 & -0.8 \\
\hline $\mathrm{P}-\mathrm{H}^{\prime} \mathrm{s} \%$ & 15.8 & 0.5 & -0.1 \\
\hline $\mathrm{P}-\mathrm{H}^{\prime} \mathrm{p} \%$ & 82.7 & -0.4 & 0.2 \\
\hline $\begin{array}{l}\mathrm{N} \text { lp } \rightarrow \sigma^{*} \mathrm{PH} \mathrm{CT}, \\
\text { me }\end{array}$ & & 2.0 & 4.6 \\
\hline
\end{tabular}

Table 2. Effects of complexation with $\mathrm{NH}_{3}$ upon properties of $\mathrm{FPH}_{2}$ molecule

\begin{tabular}{|c|c|c|c|}
\hline & monomer & $\Delta \mathrm{FP} \cdots \mathrm{N}$ & $\Delta \mathrm{PH} \cdots \mathrm{N}$ \\
\hline$-\Delta \mathrm{E}, \mathrm{kcal} / \mathrm{mol}$ & & 6.2 & 1.43 \\
\hline $\mathrm{r}(\mathrm{P}-\mathrm{F}), \AA$ & 1.674 & 0.027 & 0.006 \\
\hline $\mathrm{r}(\mathrm{P}-\mathrm{H}), \AA$ & 1.430 & -0.005 & -0.002 \\
\hline $\mathrm{r}\left(\mathrm{P}-\mathrm{H}^{\prime}\right), \AA$ & 1.430 & -0.005 & 0.0003 \\
\hline$v(\mathrm{P}-\mathrm{F}), \mathrm{cm}^{-1}$ & 778.2 & -64.7 & -9.2 \\
\hline$v(\mathrm{P}-\mathrm{H}), \mathrm{cm}^{-1}$ & 2444.6 & 15.7 & -15.6 \\
\hline$v\left(\mathrm{P}-\mathrm{H}^{\prime}\right), \mathrm{cm}^{-1}$ & 2444.6 & 15.7 & 4.7 \\
\hline$q(F), e$ & -0.635 & -0.029 & -0.005 \\
\hline$q(H), e$ & -0.094 & 0.002 & 0.039 \\
\hline$q\left(H^{\prime}\right), e$ & -0.094 & 0.002 & -0.005 \\
\hline$q(P), e$ & 0.822 & -0.025 & -0.033 \\
\hline P-F s\% & 11.4 & -2.4 & -0.1 \\
\hline P-F p $\%$ & 86.9 & 2.1 & 0.1 \\
\hline P-H s\% & 14.3 & 1.3 & 1.2 \\
\hline $\mathrm{P}-\mathrm{H} \mathrm{p} \%$ & 83.6 & -0.8 & -1.1 \\
\hline P-H's\% & 14.3 & 1.3 & 0.0 \\
\hline P-H'p $\%$ & 83.6 & -0.8 & 0.1 \\
\hline $\mathrm{CT} \mathrm{N}_{\mathrm{lp}} \rightarrow \sigma^{*} \mathrm{PF}, \mathrm{me}$ & & 33.3 & 0 \\
\hline $\mathrm{CT} \mathrm{N}_{\mathrm{lp}} \rightarrow \sigma^{*} \mathrm{PH}, \mathrm{me}$ & & 1.6 & 6.1 \\
\hline
\end{tabular}




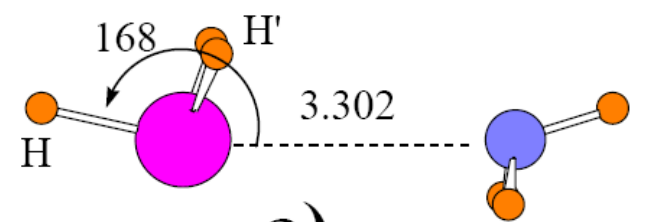

a)

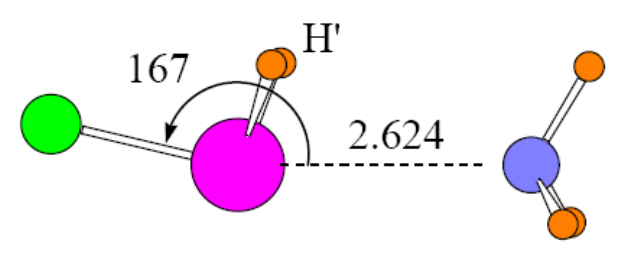

c)
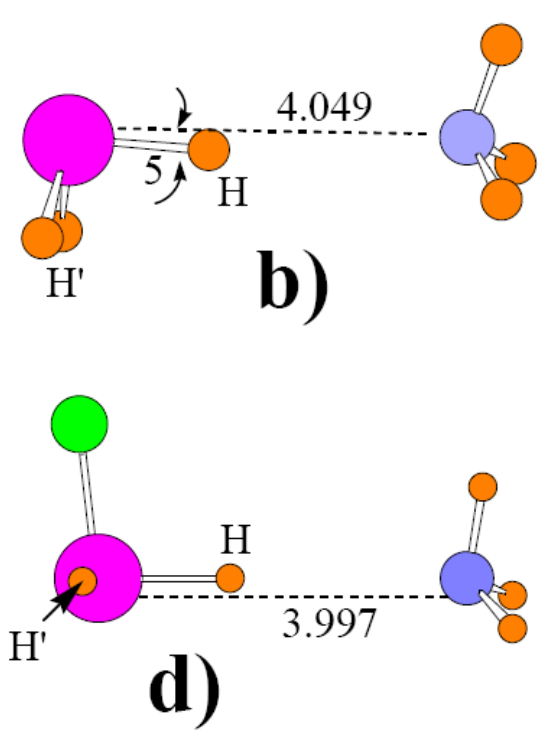

Fig 1. Atomic arrangements in the geometries of $\mathrm{PH}_{3} / \mathrm{NH}_{3}$ (a and b) and $\mathrm{FPH}_{2} / \mathrm{NH}_{3}$ (c and d). Distances in $\AA$; angles in degs. Pnicogen $\mathrm{P} \cdots \mathrm{N}$ bonds are present in a and c, and $\mathrm{PH} \cdots \mathrm{H}$ $\mathrm{H}$-bonds in $\mathrm{b}$ and $\mathrm{d}$.

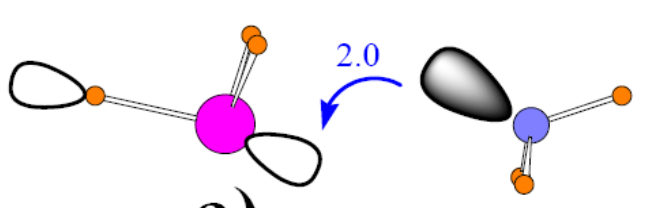

a)

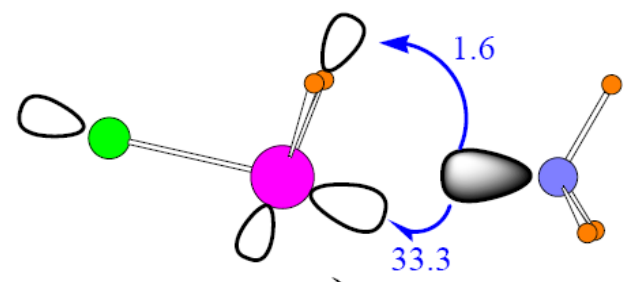

C)

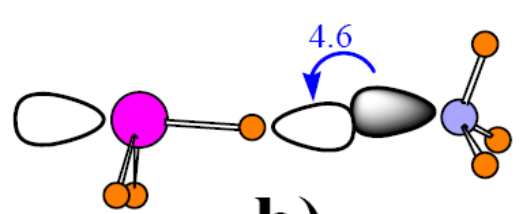

b)

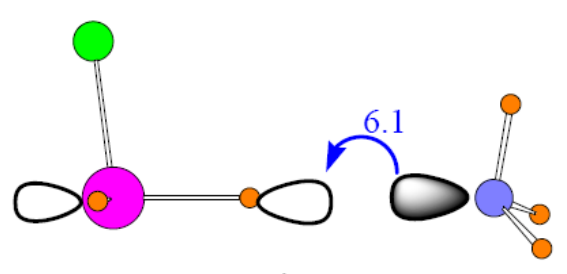

d)

Fig 2. Disposition of important orbitals. Filled lobe represents doubly occupied $\mathrm{NH}_{3}$ lone pair and the virtual $\sigma^{*}$ orbitals are depicted by unfilled lobes. Charge transfers occurring upon complexation are indicated in units of me. 
Table 1. Effects of complexation with $\mathrm{NH}_{3}$ upon properties of $\mathrm{PH}_{3}$ molecule

\begin{tabular}{|l|l|l|l|}
\hline & monomer & $\Delta \mathrm{HP} \cdots \mathrm{N}$ & $\Delta \mathrm{PH} \cdots \mathrm{N}$ \\
\hline$-\Delta \mathrm{E}, \mathrm{kcal} / \mathrm{mol}$ & & 2.1 & 1.5 \\
\hline $\mathrm{r}(\mathrm{P}-\mathrm{H}), \AA$ & 1.426 & 0.003 & 0.001 \\
\hline $\mathrm{r}\left(\mathrm{P}-\mathrm{H}^{\prime}\right), \AA$ & 1.426 & -0.002 & 0.001 \\
\hline$v(\mathrm{P}-\mathrm{H}), \mathrm{cm}^{-1}$ & 2471.2 & -22.6 & -6.5 \\
\hline$v\left(\mathrm{P}-\mathrm{H}^{\prime}\right), \mathrm{cm}^{-1}$ & 2470.6 & 9.9 & -5.9 \\
\hline $\mathrm{q}(\mathrm{H}), \mathrm{e}$ & -0.035 & -0.012 & 0.035 \\
\hline $\mathrm{q}\left(\mathrm{H}^{\prime}\right), \mathrm{e}$ & -0.035 & +0.004 & -0.006 \\
\hline $\mathrm{q}(\mathrm{P}), \mathrm{e}$ & 0.106 & -0.001 & -0.029 \\
\hline $\mathrm{P}-\mathrm{H} \mathrm{s} \%$ & 15.8 & -0.4 & 1.1 \\
\hline $\mathrm{P}-\mathrm{H}$ p\% & 82.7 & 0.4 & -0.8 \\
\hline $\mathrm{P}-\mathrm{H}^{\prime} \mathrm{s} \%$ & 15.8 & 0.5 & -0.1 \\
\hline $\mathrm{P}-\mathrm{H}^{\prime} \mathrm{p} \%$ & 82.7 & -0.4 & 0.2 \\
\hline $\begin{array}{l}\mathrm{N} \text { lp } \rightarrow \sigma^{*} \mathrm{PH} \mathrm{CT}, \\
\text { me }\end{array}$ & & 2.0 & 4.6 \\
\hline
\end{tabular}

Table 2. Effects of complexation with $\mathrm{NH}_{3}$ upon properties of $\mathrm{FPH}_{2}$ molecule

\begin{tabular}{|c|c|c|c|}
\hline & monomer & $\Delta \mathrm{FP} \cdots \mathrm{N}$ & $\Delta \mathrm{PH} \cdots \mathrm{N}$ \\
\hline$-\Delta \mathrm{E}, \mathrm{kcal} / \mathrm{mol}$ & & 6.2 & 1.43 \\
\hline $\mathrm{r}(\mathrm{P}-\mathrm{F}), \AA$ & 1.674 & 0.027 & 0.006 \\
\hline $\mathrm{r}(\mathrm{P}-\mathrm{H}), \AA$ & 1.430 & -0.005 & -0.002 \\
\hline $\mathrm{r}\left(\mathrm{P}-\mathrm{H}^{\prime}\right), \AA$ & 1.430 & -0.005 & 0.0003 \\
\hline$v(\mathrm{P}-\mathrm{F}), \mathrm{cm}^{-1}$ & 778.2 & -64.7 & -9.2 \\
\hline$v(\mathrm{P}-\mathrm{H}), \mathrm{cm}^{-1}$ & 2444.6 & 15.7 & -15.6 \\
\hline$v\left(\mathrm{P}-\mathrm{H}^{\prime}\right), \mathrm{cm}^{-1}$ & 2444.6 & 15.7 & 4.7 \\
\hline$q(F), e$ & -0.635 & -0.029 & -0.005 \\
\hline$q(H), e$ & -0.094 & 0.002 & 0.039 \\
\hline$q\left(H^{\prime}\right), e$ & -0.094 & 0.002 & -0.005 \\
\hline$q(P), e$ & 0.822 & -0.025 & -0.033 \\
\hline P-F s\% & 11.4 & -2.4 & -0.1 \\
\hline P-F p $\%$ & 86.9 & 2.1 & 0.1 \\
\hline P-H s\% & 14.3 & 1.3 & 1.2 \\
\hline P-H p $\%$ & 83.6 & -0.8 & -1.1 \\
\hline P-H's\% & 14.3 & 1.3 & 0.0 \\
\hline P-H'p $\%$ & 83.6 & -0.8 & 0.1 \\
\hline $\mathrm{CT} \mathrm{N}_{\mathrm{lp}} \rightarrow \sigma^{*} \mathrm{PF}, \mathrm{me}$ & & 33.3 & 0 \\
\hline
\end{tabular}




\begin{tabular}{|l|l|l|l|}
\hline $\mathrm{CT} \mathrm{N}_{\mathrm{lp}} \rightarrow \sigma^{*} \mathrm{PH}, \mathrm{me}$ & & 1.6 & 6.1 \\
\hline
\end{tabular}




\section{FIGURE CAPTIONS}

Fig 1. Atomic arrangements in the geometries of $\mathrm{PH}_{3} / \mathrm{NH}_{3}$ (a and b) and $\mathrm{FPH}_{2} / \mathrm{NH}_{3}$ (c and d). Distances in $\AA$; angles in degs. Pnicogen $\mathrm{P} \cdots \mathrm{N}$ bonds are present in a and c, and $\mathrm{PH} \cdots \mathrm{H}$ H-bonds in $\mathrm{b}$ and $\mathrm{d}$.

Fig 2. Disposition of important orbitals. Filled lobe represents doubly occupied $\mathrm{NH}_{3}$ lone pair and the virtual $\sigma^{*}$ orbitals are depicted by unfilled lobes. Charge transfers occurring upon complexation are indicated in units of me. 

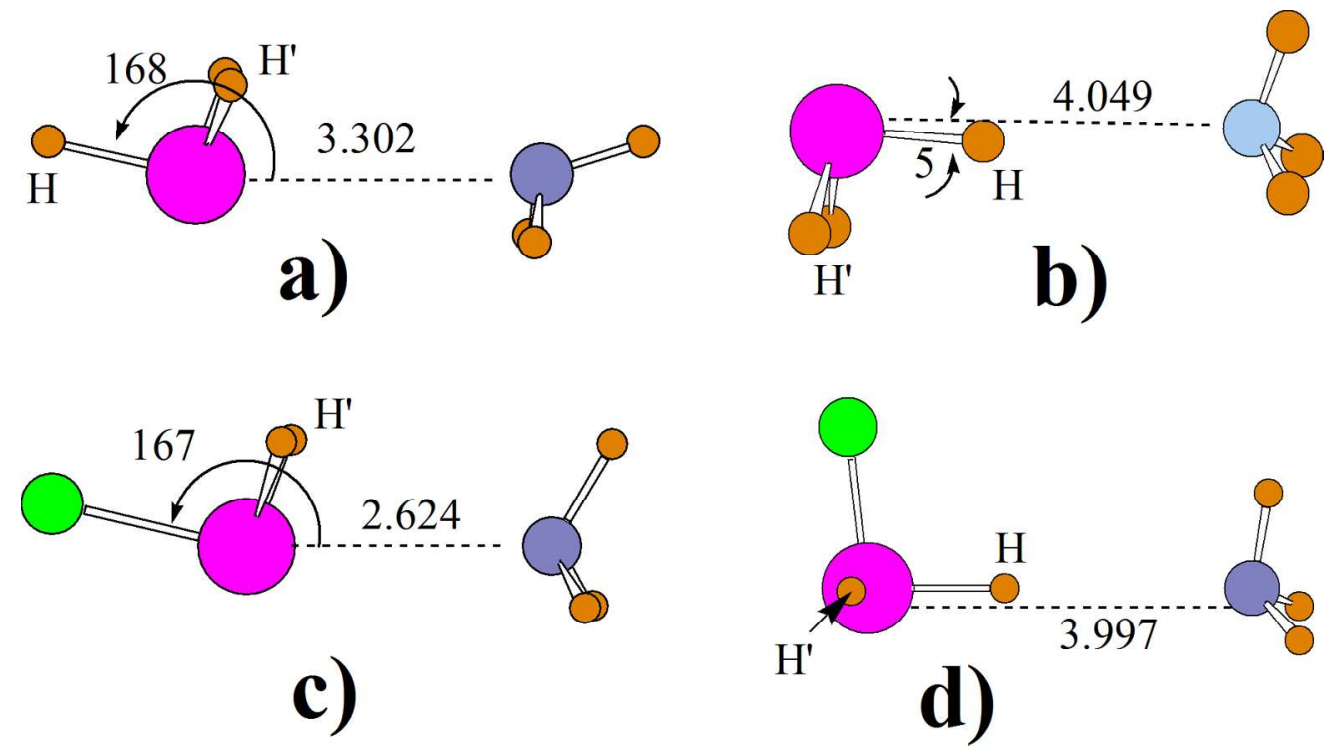

$164 \times 92 \mathrm{~mm}(300 \times 300$ DPI $)$ 


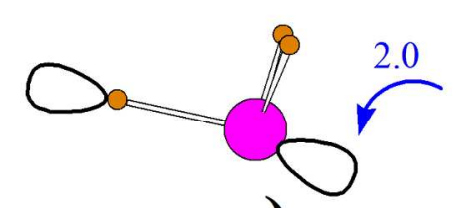

a)

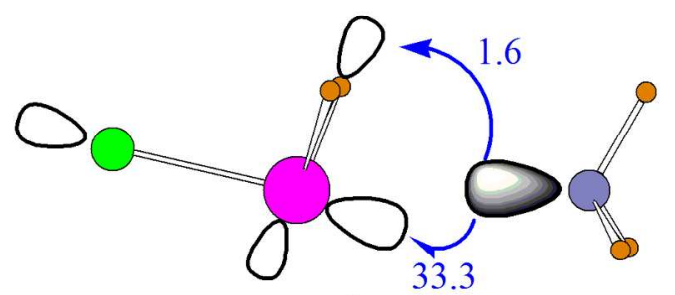

c)

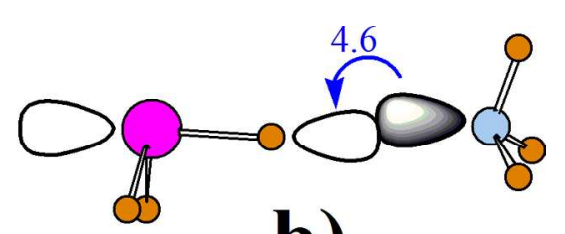

b)

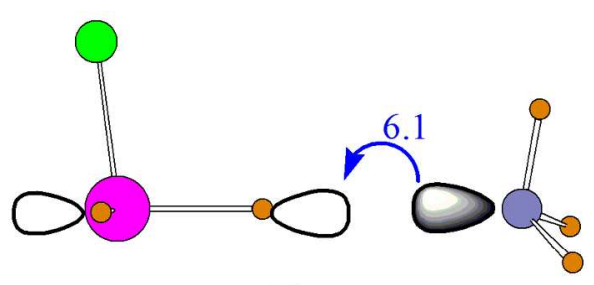

d)

$171 \times 94 \mathrm{~mm}(300 \times 300 \mathrm{DPI})$ 